$\begin{array}{ll} & \text { Etnográfica } \\ \text { etnográfica } & \text { Revista do Centro em Rede de Investigação em }\end{array}$

Antropologia

vol. $12(2) \mid 2008$

Vol. $12(2)$

\title{
Gilberto Velho (org.), Rio de Janeiro: Cultura, Política, Conflito
}

\section{Susana Durão}

\section{(2) OpenEdition \\ Journals}

\section{Edição electrónica}

URL: https://journals.openedition.org/etnografica/1831

DOI: 10.4000/etnografica.1831

ISSN: 2182-2891

\section{Editora}

Centro em Rede de Investigação em Antropologia

\section{Edição impressa}

Data de publição: 1 novembro 2008

Paginação: 568-570

ISSN: 0873-6561

\section{Refêrencia eletrónica}

Susana Durão, «Gilberto Velho (org.), Rio de Janeiro: Cultura, Política, Conflito», Etnográfica [Online], vol. 12 (2) | 2008, posto online no dia 04 julho 2012, consultado o 12 fevereiro 2022. URL: http:// journals.openedition.org/etnografica/1831 ; DOI: https://doi.org/10.4000/etnografica.1831

\section{(c) (i) (8)}

Etnográfica is licensed under a Creative Commons Attribution-NonCommercial 4.0 International License. 
Frédéric Vidal

LES HABITANTS D'ALCÂNTARA. HISTOIRE SOCIALE D'UN QUARTIER DE LISBONNE AU DÉBUT DU $20^{\text {ÉME }}$ SIÈCLE

Villeneuve d'Ascq, Presses Universitaires du Septentrion, 2006, collection

«Histoire et Civilisations», 490 páginas.

Olhar uma cidade através dos seus habitantes, procurar um determinado espaço/tempo para os encontrar, identificar um lugar como forma de chegar a esse nível mais individualizado da experiência urbana, só ela capaz de revelar a riqueza, a variedade e a dinâmica dos universos relacionais citadinos, é o eixo central deste livro. O bairro de Alcântara, na Lisboa da época industrial, é o escolhido, como um lugar integrador de formas de interacção local, de práticas relacionais, de processos de individuação/socialização que ajudam a descobrir as características de um meio social urbano "trabalhado" pelas tensões desta idade industrial. Através da pesquisa histórica sobre as formas de interacção entre os indivíduos e grupos sociais que o compõem, tanto ao nível do bairro, como entre este e o resto da cidade, o objecto desta investigação constrói-se, assim, em torno do processo de estruturação social de um determinado meio urbano. Como afirma o próprio autor, é menos o bairro em si que interessa e mais a escala de análise que, estrategicamente, permite o acesso ao estudo das proximidades e distâncias entre indivíduos e grupos sociais numa grande cidade na época em análise. Com efeito, mais do que a história social de um bairro, estamos aqui perante um trabalho de "história social à escala de um bairro" (p. 22). Aquilo que, numa escala mais macro, poderia parecer um projecto duplamente periférico - estudar um bairro industrial de uma cidade situada num país dominantemente rural que, por sua vez, se encontra à margem do processo de industrialização e urbanização em grande escala da Europa - acaba por se afirmar como um caso exemplar, na especificidade local de um fenómeno espacial e sectorialmente tão polarizado como é o da industrialização.

Versão ligeiramente abreviada da tese de doutoramento em História defendida na Universidade Lumière Lyon 2 em 2003, Les Habitants d'Alcântara organiza-se em quatro partes coerentes e bem articuladas que, respeitando o percurso da investigação, permitem ao leitor acompanhar o caminho da necessária inter-relação entre a construção dos dados empíricos e a exposição teórica, nas diferentes escalas de aproximação, do bairro ao indivíduo e das representações às formas de interacção quotidiana. Metodologicamente, a lacuna de fontes sobre sociedade lisboeta nos séculos XIX e XX é colmatada através da combinação entre a exploração de documentação variada e dispersa, incluindo 
fontes locais e microlocais, e a análise sistemática e intensiva de uma fonte única, os registos paroquiais e civis.

Após uma introdução que situa teoricamente a investigação, Frédéric Vidal começa por apresentar o bairro de Alcântara como espaço social e quadro de vida, contextualizando-o num quadro estrutural amplo - o território, a população, as actividades - e, também, ao nível da sua identidade colectiva. Alcântara não se define apenas como território delimitado, povoado por múltiplas actividades, ela é também feita de imagens que acompanham a sua evolução de bairro industrial a bairro popular: o "subúrbio (faubourg) operário", o "bastião republicano" e o "bairro popular" são mais do que três "Alcântaras" que se sucedem no curso da história, são representações, ambientes, momentos, que ligam este bairro à história de Lisboa, através da sua componente industrial e operária, por um lado, e popular e urbana, por outro.

A exploração minuciosa dos múltiplos níveis de produção de distância e de proximidade social entre indivíduos, devidamente contextualizados em função dos seus lugares de vida social, faz-se a partir da análise de uma fonte priveligiada, os registos de baptismo, nascimento e, até, casamento. Duas ruas são escolhidas como espaço sociológico para o estudo das relações interpessoais. A crítica das fontes utilizadas e uma primeira análise centrada no indivíduo e sua origem, alimenta esta segunda parte. A discussão que o autor faz a propósito das diferentes escalas de análise reveladas por estas fontes - o indivíduo, o casal, a linhagem familiar, e a vizinhança - mostram diferentes tipos de mobilidade geográfica, ultrapassando nitidamente o nível mais territorializado da rua e evidenciando os elementos de identificação cruciais dos habitantes nas suas relações com o bairro, a cidade, o país.

A dimensão socioprofissional ocupa, de forma muito clara, um lugar central nesta investigação densa (terceira e quarta parte) através do exame das práticas relacionais concretas (por exemplo, o apadrinhamento) e os factores de distinção social através de lógicas próprias, de acordo com o ofício exercido, a qualificação, o estatuto. São as formas de estruturação dos meios urbanos, nas diferentes escalas que as produzem, que aqui são analisadas e questionadas. O modo como Frédéric Vidal consegue fazer falar esta "fonte pobre" revela o seu talento de investigador que, com rigor e intuição, consegue reconstituir as histórias de famílias. É fundamental referir, também, a excelente escolha de fontes complementares que introduzem toda uma discussão sobre as classificações e identidades profissionais. A reflexão que o autor produz sobre este universo concreto, examinando meticulosamente os modos de interacção entre indivíduos e grupos com posições, status e trajectórias diferentes, constitui, sem dúvida, uma valiosa contribuição para a compreensão dos universos relacionais das sociedades urbanas contemporâneas, diversificadas, compósitas, plurais.

O papel importante que as mulheres desempenham a partir das suas práticas quotidianas de controle social do espaço do bairro, as sociabilidades de vizinhança, a circulação da informação, enfim, a produção e reprodução das distâncias e proximidades sociais constitui um dos exemplos mais impressionantes de uma omissão, uma vez que tanto nos arquivos da associação Promotora, como nos registos paroquiais ou na imprensa republicana, as informações são muito masculinizadas. Este "silêncio feminino" é muito bem problematizado pelo autor, concedendo-lhe toda uma discussão muito aprofundada. Parece claro que as mulheres lisboetas "de raiz" desempenham um papel fundamental no relacionamento e mistura de populações, mas de que modo? Como incorporar esta "metade" da sociedade na história social de Lisboa, não apenas 
na história dos bairros mas, sobretudo, na história do trabalho e das profissões ? Que temas, que metodologias, que tipo de fontes - históricas, etnográficas e outras - se pode procurar para esta démarche?

A relação entre universos relacionais e mobilidades sociais é, sem dúvida, um dos temas chave no estudo da transformação dos meios urbanos; neste caso, foi possível identificar alguns elementos fundamentais - o status socioprofissional, os itinerários individuais e sua combinação na interacção pessoal, a natureza do meio de acolhimento (conclusões). Embora este seja o eixo central da problematização desta investigação, ela não fica por aqui. Metodologicamente, há que insistir no facto de o plano microlocal das ruas, escolhido com o objectivo de operacionalizar uma delimitação necessária à recolha das fontes, se ajustar a outros níveis mais amplos de estruturação da sociedade. A selecção de uma ampla variedade de fontes permite um excelente jogo de escalas na análise dos processos observados, respeitando sempre a complementaridade entre as práticas e as representações. Por estas razões, o que aqui está em causa não é simplesmente a singularidade de um bairro, ou suas ruas, numa cidade particular, mas sim a exemplaridade de um conjunto de microprocessos sociais e culturais que, historicamente, construíram Lisboa e, por extensão ou similaridade, outras sociedades urbanas particulares.

Com efeito, esta obra impõe-se, desde já, como uma referência no seio dos estudos urbanos portugueses, nomeadamente pela sua original e assumida abertura disciplinar, visível tanto na criteriosa selecção bibliográfica como no percurso de pesquisa, integrando-se em linhas de investigação recentes do campo da sociologia e da antropologia urbanas portuguesas, orientadas por uma mesma preocupação em convocar vários campos disciplinares para o aprofundamento da análise dos microprocessos e dinâmicas fundadoras das sociedades urbanas.
Esta é uma das razões que torna esta investigação pioneira, em vários sentidos. Les Habitants d'Alcântara é o bom exemplo de como a confluência de várias tradições disciplinares e nacionais pode enriquecer exponencialmente a construção de um determinado objecto, através da incorporação de diferentes olhares e perspectivas em torno de um problema - o que, neste caso, foi levado a cabo de um modo extremamente inteligente, criativo e criterioso. Com uma dupla inserção relativamente a tradições nacionais de estudo de bairros - a historiográfica francesa e italiana dos anos 1970 e 1980 e a etnográfica portuguesa, partilhada por várias ciências sociais, que nos anos 90 lançou as bases de uma reflexão e metodologia de investigação centrada no indivíduo (para usar uma expressão de Michel Agier, em "Les savoirs urbains de l'anthropologie", Enquête, 4, 1996) - esta obra revela um modo de fazer história particularmente sedutor e motivador de múltiplos diálogos interdisciplinares, uma vez que consegue conjugar a sua vertente micro-analítica, com uma pluralidade de referências e uma assumida intenção experimental visível no modo interactivo como as fontes são trabalhadas.

Por último, não se pode deixar de referir alguns pormenores de edição que tornam este livro particularmente útil para futuros e actuais investigadores: a organização temática da bibliografia e das fontes; os anexos, com as listagens de declarações profissionais de pais e padrinhos, classificações profissionais de acordo com categorias contemporâneas (1) e historiográficas (2) e, sobretudo, um glossário bilingue (português e francês) de classificações profissionais.

Seria de saudar a publicação de uma versão em língua portuguesa desta excelente obra, que restitua ao público português os conhecimentos alcançados.

Graça Índias Cordeiro

Departamento de Antropologia e CIES-ISCTE 
Gilberto Velho (org.)

RIO DE JANEIRO:

CULTURA, POLÍTICA, CONFLITO

Rio de Janeiro, Jorge Zahar Editor, 2008, 228 páginas.

Num estilo ecléctico, abrindo muitas portas de entendimento e sublinhando as potencialidades de um método, o etnográfico, esta obra está entre aquelas que merece ser lida por muitos. Trata-se de uma colectânea que resulta da articulação de dois factores: a já maturada pesquisa de Gilberto Velho em torno dos temas da antropologia urbana e das sociedades complexas e a edição de pesquisas em curso, levadas a cabo por alunos do Programa de Pós-Graduação em Antropologia Social do Departamento de Antropologia do Museu Nacional/UFRJ. É uma obra de síntese de temas muito variados mas que tem como pano de fundo a cidade do Rio de Janeiro, em particular, e os universos urbanos, em geral.

Há muito que Gilberto Velho assumiu como responsabilidade a abertura de um campo de estudos antropológicos dos fenómenos complexos que observava na sociedade brasileira e em detalhe na cidade carioca. A lista de publicações é hoje muito extensa e foi inaugurada por essa grande inquietação intelectual que representa O Desafio da Cidade (Campus, 1980). Na última década, porém, o autor tem-se dedicado insistentemente à questão da violência no Brasil contemporâneo, por exemplo em Cidadania e Violência (FGV, 1996), Mudança, Crise e Violência (Civilização Brasileira, 2002).

Em Rio de Janeiro: Cultura, Política, Conflito, no texto de abertura escrito pelo autor, "Metrópole, cultura e conflito", podemos sublinhar dois aspectos principais para uma análise crítica contemporânea da vida urbana no Rio. Primeiro, a forma como descreve a transformação rápida de uma cidade em metrópole. Segundo, G. Velho insiste no argumento de que a convivência interidentitária, a coexistência e interacção entre diferentes segmentos sociais - base mesmo da vida nas cidades - parecem hoje encontrar-se comprometidas. Neste sentido, o autor recorre aos estudos de G. Simmel para diferenciar conflito (presente em todas as sociedades) e violência (dimensão não generalizada da vida social), defendendo que no Rio se desenvolve uma verdadeira "cultura da violência" que ultrapassou largamente os limites da conflituosidade social.

O texto lança o mote que serve de âncora aos restantes textos do livro: a cultura é o eixo privilegiado da investigação. "As diferenças em termos de visões de mundo e estilos de vida entre categorias sociais que convivem e interagem cotidianamente não são sempre óbvias ou facilmente identificáveis" (p. 12). Assim, propondo uma abordagem etnográfica, um esforço intelectual de "estranhamento do familiar", os restantes textos lançam-se na procura desses traços culturais que fazem do Rio de Janeiro a cidade que ela é, a cidade como ela é, para parafrasear o famoso cronista Nelson Rodrigues.

Os textos que se seguem são olhares próximos, etnografias situadas, que partem da reflexão de vários problemas e fenómenos que têm expressão na cidade e que oscilam criativamente entre: os bailes funk; os showmícios da política; redes sociais de músicos e professores da Baixada Fluminense; mulheres do samba; boates, estilos de vida gay e práticas homoeróticas; o mundo do heavy metal de várias zonas do Rio; camelôs e pontos de venda ambulante. Este é um aspecto a louvar só por si. Nesta obra temos a possibilidade de entrar directamente em realidades que não tendo sido etnografadas se mantiveram amplamente desconhecidas para grande parte de académicos e do público leitor em geral. 
Tal como os temas, também os estilos narrativos são variados. Por exemplo, o texto de F. Piccolo, "Os jovens entre o morro e a rua...", propõe-se tratar as questões de negociação do estatuto no acesso ao terreno de estudo (o morro de Vila Isabel, na zona norte do Rio), desenvolvendo e demorando-se sobre a sua categoria de outsider e sobre como se foi construindo uma certa familiarização com as pessoas do contexto estudado. Era não só a jovem mulher branca, não identificada como residente ou oriunda do mesmo segmento social das pessoas com quem se relacionava, mas uma recém-moradora do Rio de Janeiro, oriunda de "um outro Brasil", do Rio Grande do Sul, e amplamente desconhecedora dos morros cariocas.

Talvez em sentido inverso, o texto de S. Costa, "Vertigem em Nilópolis...", aproveita a sua experiência etnográfica para revelar, num tom confessional, desenvolvimentos autobiográficos associados à experiência de regresso ao lugar onde cresceu e de onde saiu para a ele voltar, mas agora perspectivando-o de modo antropológico. Ao olhar para a vida cultural na Baixada Fluminense, o espelho identitário mostrou-lhe conflitos subjectivos e uma certa transformação progressiva do que é familiar em estranheza e que, num momento seguinte, foi necessário deslindar.

Já M. Burns, em "A dona da voz e a voz da dona...", opta por descrever uma vida, a da compositora e sambista Dona Ivone Lara, à medida que vai sugerindo interpretações sociológicas. Por sua vez, P. Lopes, em "Mundo heavy metal no Rio de Janeiro", leva-nos no seu ombro numa viagem a vários clubes, ambientes underground, rixas e aparato simbólico destes rockeiros. Enquanto isso, procura explicar como se formulam identidades juvenis, zonas de gosto e o seu próprio interesse pessoal na escolha deste objecto de estudo.

Os textos da obra não se centram apenas nas questões que à “tecnologia da produção antropológica" dizem respeito, e talvez por isso sejam tão interessantes.

Ao usarem ferramentas disponíveis para conhecer e descrever o que observam, ao usarem quer modalidades narrativas mais introspectivas e autobiográficas, quer visões menos atravessadas por envolvimentos pessoais, os textos vão oferecendo dados relevantes para a interpretação das plurais e multi-situadas realidades urbanas.

O texto de A. Barreto, "Sobre palanques e palcos..." é, quanto a mim, dos mais bem conseguidos na articulação entre a proposta metodológica e a interpretação dos dados. Usa uma metodologia criativa para observar na sua extensão e plasticidade o papel dos showmícios na vida política-partidária local. Ao mesmo tempo, o texto é relevante para evidenciar as relações entre dinamismos políticos, culturais e económicos da cidade.

Outro texto bem conseguido é o de M. Benítez, "Buraco da Lacraia...", na medida em que evidencia a presença do corpo e das marcas de raça, classe, género, idade e estilos nas interacções interpessoais e, em particular, nos intercâmbios homoeróticos estabelecidos.

Por fim, P. Mafra, em "Camelôs cariocas", oferece uma pitada do que pode vir a ser uma boa etnografia, circulando com os vendedores ambulantes do Rio de Janeiro e que, sendo alvo de políticas restritivas e de controlo policial, evidenciam uma actividade que não cessa de crescer. Seria certamente muito interessante, todavia arriscado, penetrar os canais de influência e de expansão local/global dos pequenos e grandes camelôs.

O que se revela atraente nesta obra é como a sua estrutura e organização reflecte em grande medida o que é perceptível para a maioria dos cariocas e para quem com eles convive um dado período da sua vida. Se, por um lado, é inegável uma geografia da violência, terrenos e itinerários dos 
problemas: crescendo de violência armada e ligações opacas entre política, crime, polícia, por outro lado, o Rio de Janeiro é uma cidade que não cessa de fervilhar nas suas opções culturais, de sociabilidade múltipla, nas trocas de experiências e de estilos de vida e até mesmo na afirmação de novos mercados locais e de possibilidades, formais ou informais, que fazem da economia e da sociedade brasileira um exemplo de dinamismo no mundo.
Assim, qualquer retrato sociológico do Rio de Janeiro que não contemple pelo menos o cruzamento entre estas duas leituras da realidade quotidiana - que para simplificar se poderiam determinar como uma mais crítica e outra mais aberta à surpresa - não pode oferecer um quadro coerente do que ali se passa.

\section{Susana Durão}

Investigadora auxiliar do ICS-UL 